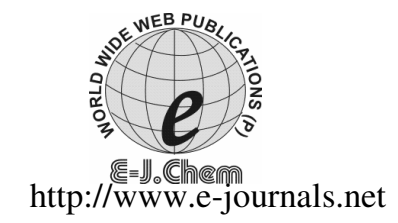

\title{
A Convenient Access to Biquinoline Carbaldehydes using Nickel-Phosphine Complex-Mediated Homocoupling of Haloquinoline Carbaldehydes in One-Pot Reaction
}

\author{
AHMED BENAMEUR*, TAOUES BOUMOUD, \\ BOUDJEMAA BOUMOUD ${ }^{\S}$ and SALAH RHOUATI
}

Laboratoire des Produits Naturels d'origine Végétale et de Synthèse,

Organique. Département de Chimie. Faculté des Sciences,

Université Mentouri de Constantine 25000 Constantine, Algérie.

ta_boumoud@yahoo.fr

Received 10 October 2009; Revised 10 December 2009; Accepted 4 February 2010

\begin{abstract}
The homocoupling of 2-chloro-carbaldehyde derivatives gave the corresponding 2,2'-biquinolines by using the in situ generated reactive reagent $\mathrm{Ni}\left[\left(\mathrm{PPh}_{3}\right)\right]_{4}$. Several new 2-chloro-3-(1.3 dioxalan-2yl) quinoline derivatives are synthesized and structurally characterized. The overall structures of biquinoline derivatives are not planar.
\end{abstract}

Keywords: 2-Chloroquinoline carbaldehyde, Homocoupling, One-pot reaction, 2,2'-Biquinoline derivatives.

\section{Introduction}

There is growing interest in the chemistry of biquinoline compounds due to the possibility of their use in high performance heterocyclic ladder polymers ${ }^{1}$, as ligands for the preparation of metal complexes bearing biological activities, such as antibacterial, antifungal, antimalarial and antitumor properties and as hydrogenation catalysts ${ }^{2-4}$. Even though there are several synthetic methods of biquinoline derivatives cited in the literature ${ }^{5}$, most of them suffer from some drawbacks such as low yields due to the formation of by-products, the use of highly reactive coupling reagents and competitive reductions from the presence of protonic sources ${ }^{6,7}$.

To overcome these difficulties, we describe herein an efficient one-pot synthesis of some new biquinoline carbaldehyde derivatives which consists of the homocoupling of haloquinolines mediated by nickel-phosphine complexes. This method is based on the procedure described by Tiecco et al. ${ }^{8}$, which uses the in situ generated nickel(0) complex.

To surmount the well known competitive reduction of aldehyde function and haloheterocycles by $\mathrm{Zn}(0)$ in the presence of a proton source such as water ${ }^{6}$, we protected the aldehyde function using ethylene glycol in the presence of montmorillonite (K10) ${ }^{9}$. The amount 
of zinc dust was added in portions to a solution of $\mathrm{PPh}_{3}$ and $\mathrm{NiCl}_{2} \cdot 6 \mathrm{H}_{2} \mathrm{O}$ in DMF at $70{ }^{\circ} \mathrm{C}$ under argon followed by the addition of the protected 2-chloroquinoline carbaldehyde $\mathbf{2}$ (Scheme 1).<smiles>[R]c1cc2nc(-c3nc4cc([R])c(C5OCCO5)cc4cc3C3OCCO3)c(C3OCCO3)cc2cc1Br</smiles>

\section{Experimental}

Scheme 1

${ }^{1} \mathrm{H}$ NMR spectra were recorded on a BRUKER AC spectrometer (200 or $300 \mathrm{MHz}$ ) using $\mathrm{CDCl}_{3}$. Chemical shifts are reported in parts of million (ppm) relative to TMS (0.0) as internal standard and coupling constant $(J)$ is reported in hertz $(\mathrm{Hz}) .{ }^{13} \mathrm{C}$ NMR spectra were recorded on a BRUKER AC spectrometer ( 75 or $50 \mathrm{MHz}$ ). High resolution mass spectral analysis (HR-MS) were performed by CMPO (the Centre regional de Mesure de Physique de l'Ouest, Rennes, France) on a ZabSpecTOF (LSIMS, 4KV) and presented as m/e (relative intensity, assignment).

Zinc powder was washed successively with diluted hydrochloride acid, water, ethanol, acetone and diethyl ether and dried under reduced pressure. Anhydrous DMF was purified to remove traces of $\mathrm{HCN}^{10}$. All other reagents were commercially available and were purified or used as such.

The 2-chloroquinoline carbaldehyde derivatives (2), from which the present synthesis is initiated, were prepared from the corresponding acetanilide using the method reported by Meth$\mathrm{Cohn}^{11}$ (Scheme 2).

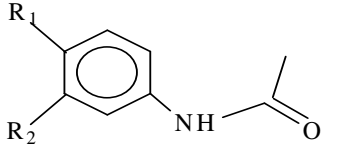

1

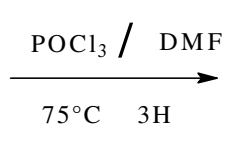

Scheme 2<smiles>[R]c1cc2cc(C=O)c(Cl)nc2cc1[R]</smiles>

2

\section{General procedure for the synthesis of biquinoline derivatives}

Zinc dust (127 mg, $1.92 \mathrm{mmol})$ was added in portions to a stirred deep blue solution of $\mathrm{NiCl}_{2} \cdot 6 \mathrm{H}_{2} \mathrm{O}(428 \mathrm{mg}, 1.8 \mathrm{mmol})$ and triphenylphosphine $(1.9 \mathrm{~g}, 7.2 \mathrm{mmol})$ in degassed DMF $(20 \mathrm{~mL})$ at $70{ }^{\circ} \mathrm{C}$ under argon. The resulting mixture was stirred for $1 \mathrm{~h}$, the time necessary for $\mathrm{Ni}(0)$ formation (red-brown color). 2-Chloro-3-(1.3 dioxalan-2yl) quinoline derivative (1.8 mmol) dissolved in degassed DMF $(10 \mathrm{~mL})$ was added drop wise and the mixture was stirred for a further $3 \mathrm{~h}$. Upon cooling to room temperature, the reaction mixture was poured into a dilute ammonia solution $(5 \%, 30 \mathrm{~mL})$, the resulting solution was extracted with $\mathrm{CH}_{2} \mathrm{Cl}_{2} / \mathrm{Et}_{2} \mathrm{O}(3 \times 100 \mathrm{~mL}, 2 / 1)$ and evaporated. The residue obtained was dissolved in $\mathrm{CH}_{2} \mathrm{Cl}_{2}(60 \mathrm{~mL})$, washed with water $(4 \times 20 \mathrm{~mL})$ and the combined organic layers were extracted with a saturated solution of $\mathrm{NaCl}(40 \mathrm{~mL})$, dried over anhydrous $\mathrm{MgSO}_{4}$ and then concentrated to give the crude product which was purified by column chromatography on silica gel using ethyl acetate / pentane (1/1) as eluent to afford the corresponding biquinoline derivative in pure state.

All compounds obtained according to this protocol were characterized and identified by NMR, mass spectra and elemental analysis. The results are summarised in Table 1. 
Table 1. $\mathrm{Ni}\left[\left(\mathrm{PPh}_{3}\right)\right]_{4}$ catalyzed synthesis of biquinoline derivatives

\begin{tabular}{cccc}
\hline${\text { Biquinoline } \mathbf{3}^{\mathrm{a}}}$ & $\mathrm{R}_{1}$ & $\mathrm{R}_{2}$ & Yield $^{\mathrm{b}} \%$ \\
\hline 3a & $\mathrm{H}$ & $\mathrm{H}$ & 53 \\
3b & $\mathrm{H}$ & $\mathrm{OMe}$ & 60 \\
3c & $\mathrm{OMe}$ & $\mathrm{OMe}$ & 56 \\
3d & $\mathrm{Me}$ & $\mathrm{Me}$ & 65 \\
\hline
\end{tabular}

${ }^{a}$ The products were characterized by their mass, ${ }^{1} \mathrm{H},{ }^{13} \mathrm{C} \mathrm{NMR}$ and elemental analysis ${ }^{b}$ Yield based on the amount of starting compound employed and calculated from the amount of product isolated by column chromatography.

\section{Spectral data for all the compounds}

[3,3-Bis[1,3]dioxalan-2-yl]-2,2']biquinoline (3a)

${ }^{1} \mathrm{H}$ NMR $\left(\mathrm{CDCl}_{3}\right): \delta(\mathrm{ppm})=8.60(\mathrm{~s}, 2 \mathrm{H}, H 4), 8.17(\mathrm{~s}, 2 \mathrm{H}, H 5), 7.96(\mathrm{~d}, 2 \mathrm{H}, H 8), 7.79(\mathrm{~d}, 2 \mathrm{H}$, H7), $7.62(\mathrm{~d}, 2 \mathrm{H}, H 6), 6.41(\mathrm{~s}, 2 \mathrm{H}, \mathrm{CH}), 3.94\left(\mathrm{~m}, 8 \mathrm{H}, \mathrm{CH}_{2}\right) ;{ }^{13} \mathrm{C} \mathrm{NMR}\left(\mathrm{CDCl}_{3}\right): \ddot{\mathrm{a}}(\mathrm{ppm})=157.4$, 147.6, 135.4, 131.4, 130.5, 129.7, 128.5, 127.7, 127.5, 101.2, 65.4; HR-MS.FAB ${ }^{+}(\mathrm{m} / z) 400.14231$ ([M+] (calc.: 400.1423). Elemental analysis (\%) for $\mathrm{C}_{24} \mathrm{H}_{20} \mathrm{~N}_{2} \mathrm{O}_{4}: \mathrm{C}$ (71.99), $\mathrm{H}(5.03), \mathrm{N}$ (7.00), Calc.: C (72.05), H (5.12), N (6.70). Yellow-brown solid.

\section{[3,3-Bis[1,3]dioxalan-2-yl]-7,7'-dimethoxy[2,2']biquinoline (3b)}

${ }^{1} \mathrm{H} \mathrm{NMR}\left(\mathrm{CDCl}_{3}\right): \delta(\mathrm{ppm})=8.5(\mathrm{~s}, 2 \mathrm{H}, H 4), 7.83(\mathrm{~d}, 2 \mathrm{H}, H 5), 7.5(\mathrm{~s}, 2 \mathrm{H}, H 8), 7.26(\mathrm{~d}, 2 \mathrm{H}, H 6)$, $6.25(\mathrm{~s}, 2 \mathrm{H}, \mathrm{CH}), 4.02\left(\mathrm{~m}, 4 \mathrm{H}, \mathrm{CH}_{2}\right), 3.96\left(\mathrm{~s}, 6 \mathrm{H}, \mathrm{OCH}_{3}\right), 3.85\left(\mathrm{~m}, 4 \mathrm{H}, \mathrm{CH}_{2}\right) ;{ }^{13} \mathrm{C} \mathrm{NMR}\left(\mathrm{CDCl}_{3}\right.$, $75 \mathrm{MHz}, \mathrm{ppm}): \delta=161.6,152.6,146.1,135.1,129.4,128.9,122.9,120.8,107.7,101.3,65.5,56.0$; HR.MS.FAB ${ }^{+}(m / z) 460.16344$ ([M+] (calc.: 460.1612); Elemental analysis (\%) for $\mathrm{C}_{26} \mathrm{H}_{24} \mathrm{~N}_{2} \mathrm{O}_{6}$ : C (67.82), H (5.25), N (6.08), Calc.: C (68.04), H (5.65), N (5.88). White solid.

\section{[3,3-Bis[1,3]dioxalan-2-yl]-6,7,6',7'-tetramethoxy-[2,2']biquinoline (3c)}

${ }^{1} \mathrm{H}$ NMR $\left(\mathrm{CDCl}_{3}\right): \delta(\mathrm{ppm})=8.43(\mathrm{~s}, 2 \mathrm{H}, H 4), 7.50(\mathrm{~s}, 2 \mathrm{H}, H 5), 7.18(\mathrm{~s}, 2 \mathrm{H}, H 8), 6.19$ (s, 2H, $\mathrm{CH}), 4.07\left(\mathrm{~s}, 6 \mathrm{H}, \mathrm{OCH}_{3}\right), 4.04\left(\mathrm{~s}, 6 \mathrm{H}, \mathrm{OCH}_{3}\right), 3.91\left(\mathrm{~m}, 8 \mathrm{H}, \mathrm{CH}_{2}\right) ;{ }^{13} \mathrm{C} \operatorname{NMR}\left(\mathrm{CDCl}_{3}\right): \delta(\mathrm{ppm})=$ 155.2, 153.4, 150.5, 144.8, 133.6, 129.3, 123.35, 108.4, 105.6, 101.4, 65.5, 56.5 ; Elemental analysis (\%) for $\mathrm{C}_{28} \mathrm{H}_{28} \mathrm{~N}_{2} \mathrm{O}_{8}, \mathrm{C}$ (64.61), $\mathrm{H}$ (5.42), N (5.38), (calc.: C (64.67), H (5.55), N (5.52); HR-MS.FAB $^{+}(\mathrm{m} / z) 520.18457([\mathrm{M}+]$ (calc.: 520.1831). White solid.

\section{[3,3-Bis[1,3]dioxalan-2-yl]-6, 7,6',7-'tetramethyl-[2,2'] biquinoline (3d)}

${ }^{1} \mathrm{H} \mathrm{NMR}\left(\mathrm{CDCl}_{3}\right): \delta(\mathrm{ppm})=8.45(\mathrm{~s}, 2 \mathrm{H}, H 4), 7.91(\mathrm{~s}, 2 \mathrm{H}, H 8), 7.66(\mathrm{~s}, 2 \mathrm{H}, H 5), 6.29(\mathrm{~s}, 2 \mathrm{H}$, $\mathrm{CH}), 4.19-4.08\left(\mathrm{~m}, 8 \mathrm{H}, \mathrm{CH}_{2}\right), 2.48\left(\mathrm{~s}, 12 \mathrm{H}, \mathrm{CH}_{3}\right) ;{ }^{13} \mathrm{C} \mathrm{NMR}\left(\mathrm{CDCl}_{3}\right): \delta(\mathrm{ppm})=156.6,146.7$, $140.8,137.3,134.4,130.4,129.1,127.6,126.2,101.4,65.4,20.9,20.5$. White shiny crystals.

Furthermore, the crystal structure of $\mathbf{3 d}$ was determined (Figure 1).
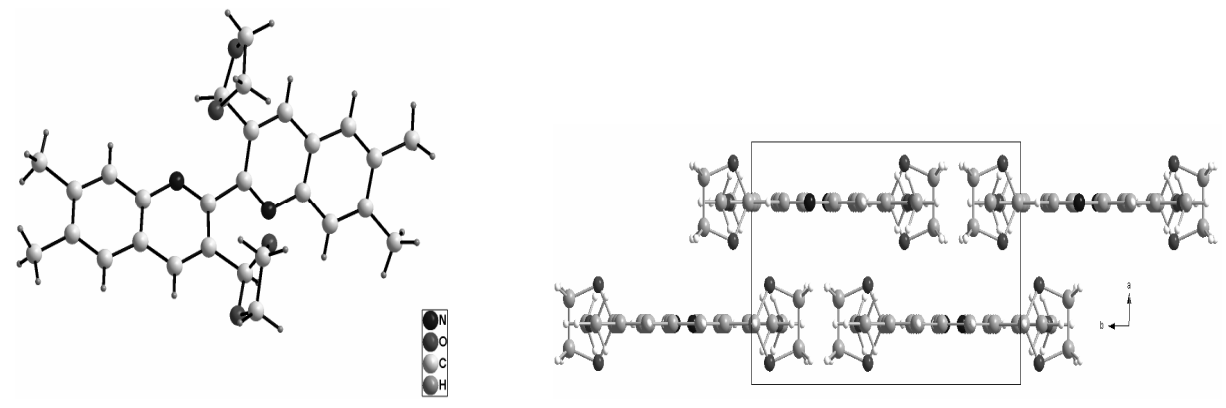

Figure 1. The crystal structure of $\mathbf{3 d}$ 


\section{Results and Discussion}

We would like to disclose here our preliminary results using the in situ generated $\mathrm{Ni}(0)$ complex, $\left[\left(\mathrm{PPh}_{3}\right)\right]_{4} \mathrm{Ni}$, for the preparation of some 2,2'-biquinoline derivatives (3).

After some exploratory experiments, we determined that the best results to produce $\mathbf{3}$ were achieved on adding zinc dust $(1.92 \mathrm{mmol}))$ to a solution of nickel(II) chloride hexahydrate $(1.8 \mathrm{mmol})$ and triphenyphosphine $(7.2 \mathrm{mmol})$ in degassed dimethylformamide $(20 \mathrm{~mL})$ under argon at $70{ }^{\circ} \mathrm{C}$ followed by the addition of 2-chloro-3-(1.3 dioxalan-2yl) quinoline derivative (1.8 mmol). The method seems to be generally applicable, thus substituted 2-chloro-3-(1.3 dioxalan-2yl) quinoline underwent the homocoupling to afford the corresponding biquinolines under the above described conditions.

In summary, the present method for the synthesis of 2,2'-biquinoline-carbaldehydes has overcome some difficulties by using the modified procedure of Tiecco et al. ${ }^{8}$.

\section{Conclusion}

In conclusion, we have synthesized and characterised some new biquinoline carbaldehyde derivatives by using the modified procedure of Tiecco et al. ${ }^{8}$ in which a stoichiometric amount of a nickel coupling reagent was used. The generation of $\left[\left(\mathrm{PPh}_{3}\right)\right]_{4} \mathrm{Ni}^{\circ}$ was conducted by the $\mathrm{Zn}(0)$ reduction of $\mathrm{NiCl}_{2} \cdot 6 \mathrm{H}_{2} \mathrm{O}$ in the presence of $\mathrm{PPh}_{3}$.

\section{Acknowledgments}

We wish to thank the "Ministère de l'Enseignement Supérieur et de la Recherche Scientifique" for financial support of this work.

\section{References}

1. Rezaei B, Meghdadi S and Bagherpour S, Sensors J, IEEE, 2008, 8(8), 1469-1477. (b) Case F H and Lafferty J J, J Org Chem., 1958, 23, 1375; (c) Rapport H, Iwamoto R and Tretter J R, J Org Chem., 1960, 25, 372; (d) Jackson G, Sasse W and Whittle C P, Aust J Chem., 1963, 16, 1126 and references cited therein.

2. Raynes K, Foley M, Tilley L and Deady L W, Biochem Pharmacol., 1996, 52, 551-559.

3. Ali Basem F, Al-Sou'od K, Al-Ja' ar N, Nasser A, Zaghal M H, Judeh Z, Al-Far R, Al-Refai M, Ibrahim M, Mansi K and Al-Obaidi K H, J Coord Chem., 2006, 59(2), 229.

4. (a) Zassinivich G, Camus A and Mestroni G, Inorg Nucl Chem Lett., 1976, 12, 865; (b) Reddy G K N, Halesha R, Leelamani E G and Gowda N M N, Proc Ind Nat Sci Acad., 1986, 52A, 1103; (c) Cleare M J, Coord Chem Rev., 1974, 12, 349; (d) Ramesh B R, Mallikarjuna B S S and Reddy G K N, Nat Acad Sci Lett., 1978, 1, 24.

5. Ramfield P and Quan P M, Synthesis, 1978, 537-538; March J, J Advanced Organic Chemistry, $3^{\text {rd }}$ Ed., Wiley Interscience, New York, 1985, 547.

6. Oparine M P, Chem Ber., 1931, 64, 569; Bak B J, J Org Chem., 1956, 21, 797.

7. Nakano S, J Pharm Soc Japan, 1959, 79, 310, 314

8. Tiecco M, Testafferi L, Tingolli M, Chianelli D and Montanucci M, Synthesis, 1984, 736.

9. Anderson L C, Pinnick H W, J Org Chem., 1978, 43, 3417.

10. Newkome G R, Robinson J M, Tetrahedron Lett., 1974, 691.

11. (a) Meth-Cohn O, Narine B, Tarnowski B, J Chem Soc., Perkin Trans I, 1980, 1520;

(b) Paul S, Gupta M, Gupta R, Synlett, 2000, 8, 1115. 


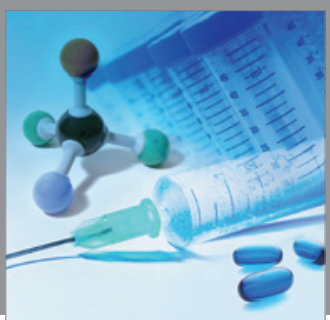

International Journal of

Medicinal Chemistry

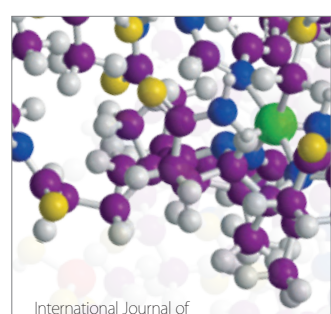

Carbohydrate Chemistry

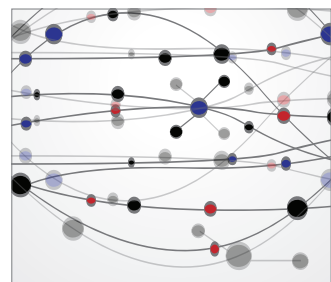

The Scientific World Journal
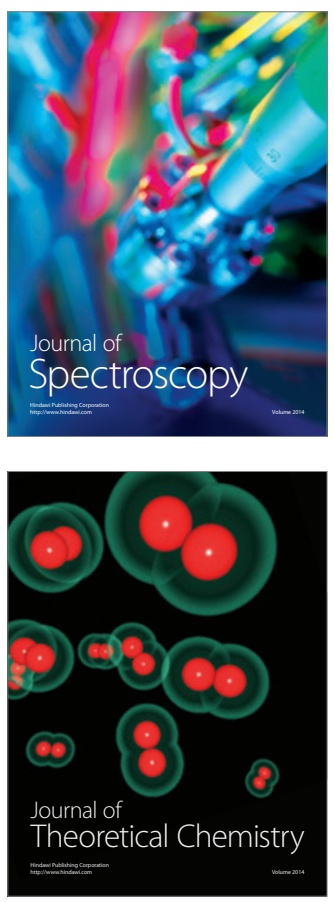
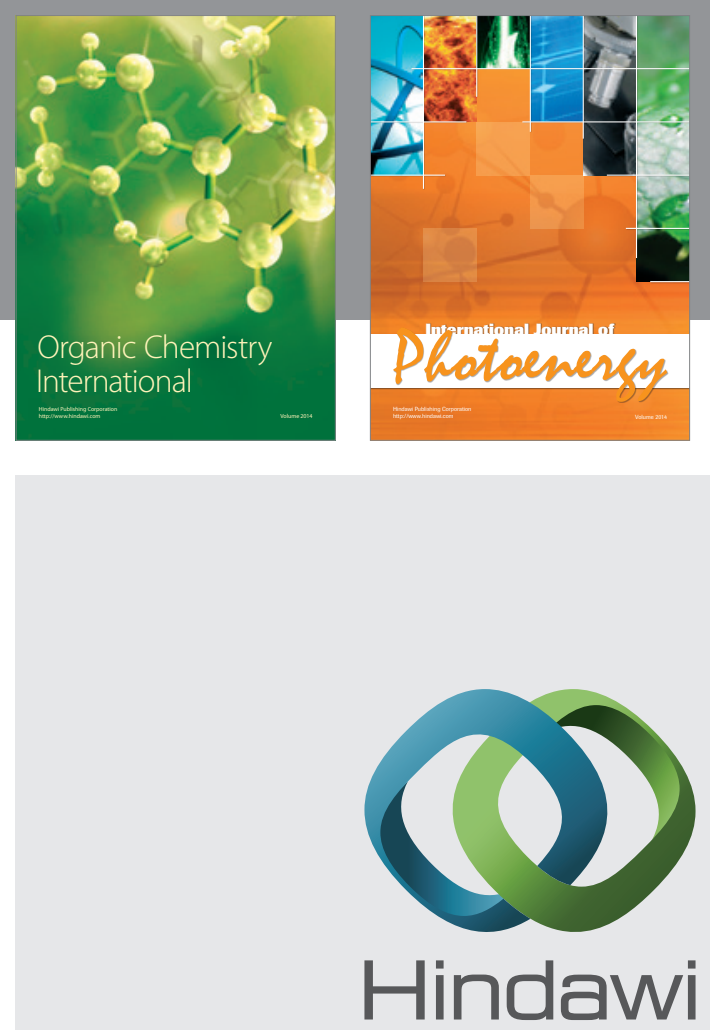

Submit your manuscripts at

http://www.hindawi.com
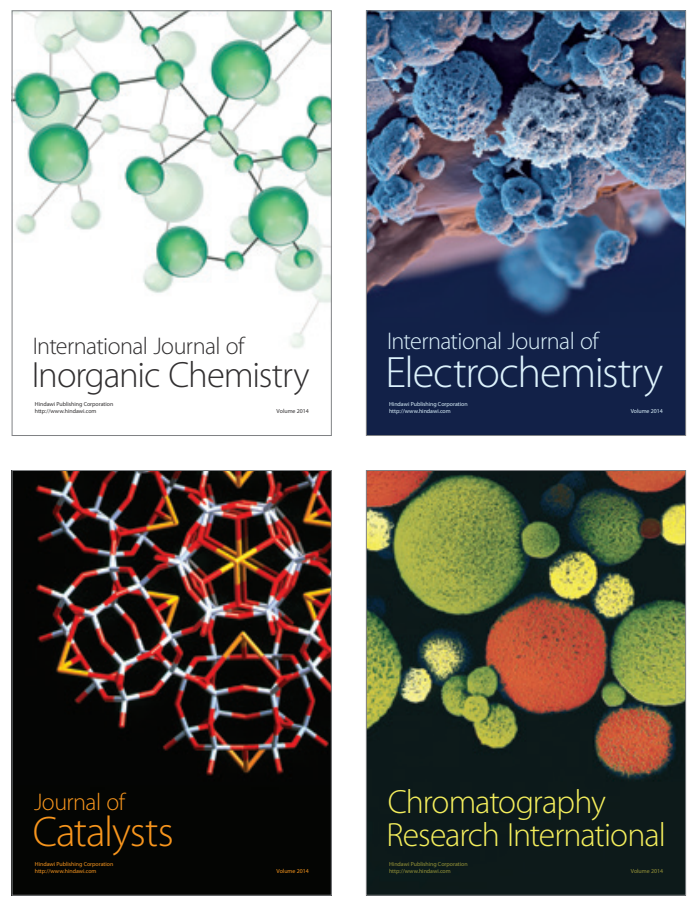
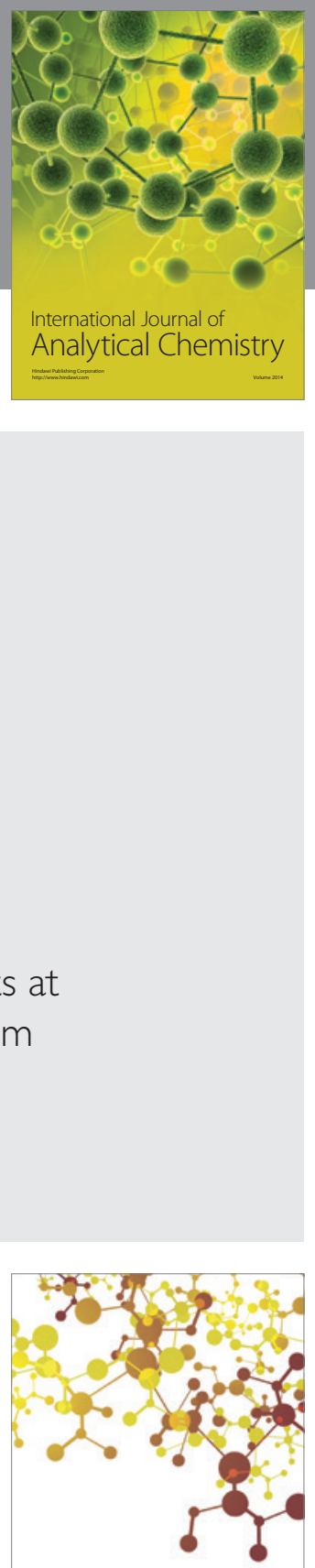

Journal of

Applied Chemistry
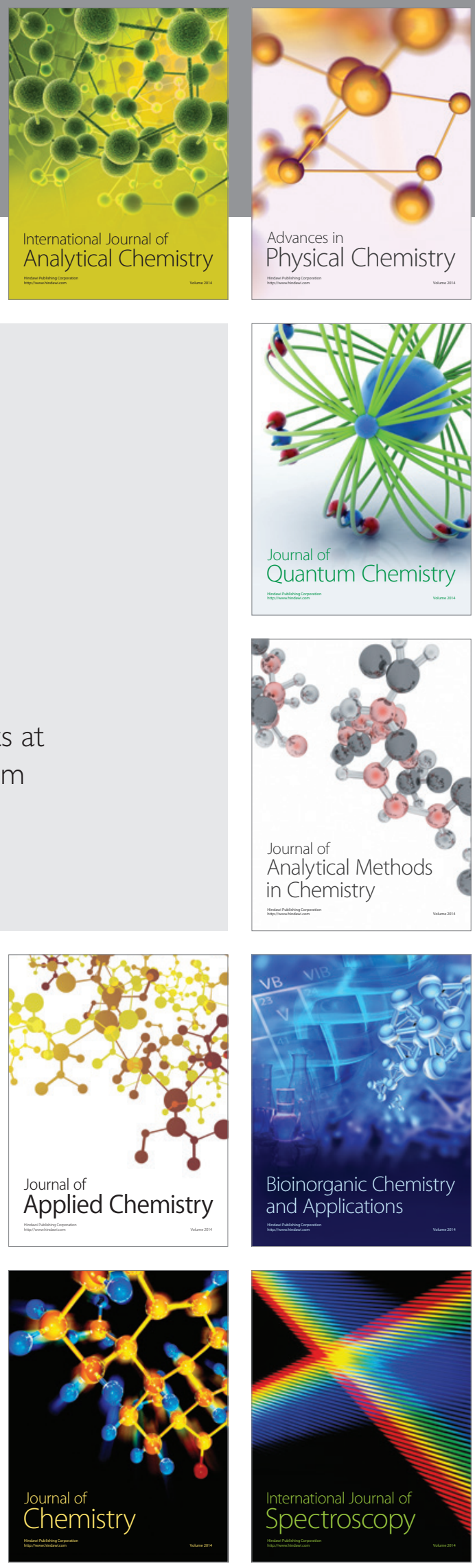